\title{
Innovation Analysis of Energy Management in Large Buildings
}

\author{
Miaoxian $\mathrm{Xu}^{1, \mathrm{a}}$
}

${ }^{1}$ Xianju County Bureau of housing and urban rural construction, Xianju, Zhejiang, 317300

${ }^{a}$ email

\section{Keywords: Large Buildings, Energy Management, Innovation Analysis}

\begin{abstract}
With the acceleration of urbanization in China, the proportion of large public buildings in urban buildings has increased rapidly. At present, China's large public buildings has more than 10,000 , with a total area of about 5 to 600 million $\mathrm{m}^{2}$, the proportion of its urban construction area of less than $4 \%$, but the electricity consumption accounts for the total cost of urban construction More than 22\%, for the ordinary residential 10-20 times, is Europe, Japan and other developed countries similar to the building 1.5 to 2 times its energy consumption accounts for about $30 \%$ of the total energy consumption, is a typical energy consumption, At the same time, China is also the focus of building energy conservation areas. In view of the energy saving and emission reduction of large public buildings, our government and relevant functional departments have issued a series of supervision guidelines, norms, standards and programs, which require energy monitoring, energy consumption statistics, energy auditing, energy efficiency publicity Energy consumption monitoring platform, the implementation of fixed energy and other energy-saving regulatory measures.
\end{abstract}

\section{Introduction}

Large public buildings as a special building in the building, refers to the single building area of $20,000 \mathrm{~m} 2$ or more, and the use of central air conditioning office, commercial, tourism, science and education, communications and transportation hub and other public buildings. At present, the total number of large public buildings in China has more than 10,000, an area of about 5 to 600 million $\mathrm{m} 2$, the power consumption of $70 \sim 300 \mathrm{kwh} / \mathrm{m} 2 \cdot$ years, 10-20 times the ordinary residential, is Europe, Japan 1.5-2 times the same type of building in developed countries. According to statistics, China's national office buildings and large public buildings in the use of the process of energy consumption accounts for about 30\% of the total energy consumption. Today, building energy consumption has been with industrial energy consumption, traffic energy together as China's three "big energy consumption." With the rapid development of China's urban construction, it is expected that by 2020, China will add about 1 billion $\mathrm{m} 2$ of large public buildings, when the task of large-scale public buildings energy saving will be more severe.

On the other hand, large-scale public buildings as an important part of China's building energy consumption, energy-saving potential is huge, is the focus of building energy efficiency areas. It is estimated that China's public building energy-saving potential is generally more than $30 \%$, for some large public buildings can even reach more than $50 \%$, and about $90 \%$ of China's large public buildings is a typical large energy consumption. Therefore, large-scale public buildings have energy-saving emission reduction, duty-bound, long way to go. There are many factors in the high energy consumption of large public buildings in China, but one of the main factors is that for a long time, China's lack of effective supervision of large-scale public building energy conservation, large public building energy consumption dynamic monitoring platform construction is relatively lagging behind, no large public Building energy consumption statistics, energy efficiency assessment, energy auditing, and energy efficiency publicity work, which makes large public buildings, energy management extensive, but also talked about large-scale public buildings, energy consumption forecast and fixed energy. The energy conservation problem of large public buildings has aroused great attention from our government and relevant functional departments. China has formulated and promulgated a series of guidelines, norms and standards for energy consumption monitoring and energy conservation supervision of large public buildings. "State organs office buildings and large public building energy auditing guidelines", "state organs office buildings and large public buildings 
energy consumption monitoring system sub-energy data collection technology guidelines", "state organs office buildings and large public buildings energy consumption Monitoring system of energy consumption data transmission technology guidelines "," state organs office buildings and large public building energy consumption monitoring system "," state organs office buildings and large public buildings energy consumption monitoring system software development guide "," state organs Office buildings and large public buildings energy consumption monitoring system construction, acceptance and operation management practices "to regulate and guide China's large-scale public buildings, energy-saving design, operation, and transformation. In addition, around the large-scale public buildings of energy-saving regulation, our government has also issued a large public building energy consumption monitoring and energy conservation supervision and regulations. June 2007, "the State Council on the issuance of comprehensive energy-saving emission reduction program of work notice" clearly pointed out that the establishment and improvement of large-scale public buildings energy-saving operation of the regulatory system, requiring the country's 32 demonstration provinces and cities to establish large-scale public building energy consumption Statistics, energy audits, energy efficiency publicity and energy consumption quota system.

\section{Large Public Building Energy Consumption Wireless Monitoring}

To monitor and manage the energy consumption of large public buildings, we need to build a large public building energy consumption monitoring system on the basis of clear monitoring contents, system structure and function, and carry out hardware design and software debugging of the core equipment in the monitoring system The Therefore, this chapter first discusses the contents of large-scale public building energy consumption collection, monitoring system architecture and function; and then focus on the monitoring system in the two types of core equipment, ZigBee energy wireless receiver terminal node and ZigBee / Ethernet gateway Hardware design, and the monitoring system of three types of energy consumption acquisition node for software development and debugging.

The basic data of the building refer to the basic situation data of the building, such as the name of the building, the construction age, the building address, the building function, the building layer, the total building area, the heating area, according to the different characteristics of the building function, scale and energy use Area, air conditioning area, building heating system form, building air conditioning system form. In addition, according to the characteristics of the building and the characteristics of energy, building basic data can also have additional items, such as: the number of staff in office buildings, shopping malls in the average daily traffic, operating time, hotel building stars, occupancy rate, Grade, cultural and educational construction of the number of students, the number of school students, medical and health building grade, gymnasium building attendance or traffic and so on. Classification of energy consumption data according to the different types of building energy, can be divided into six kinds, namely: electricity, water consumption, gas consumption, centralized cooling consumption, central heating heat consumption, other energy use. Sub-energy data refers to the corresponding power classification under the four sub-energy consumption data, namely: lighting socket electricity, air conditioning electricity, power consumption and special electricity. The four items of large public building electricity are required. In addition, according to the actual situation of building energy system, the sub-items can be further subdivided into primary and secondary sub-items, is the sub-item.

The main content of energy consumption monitoring in large public buildings is the energy consumption index of large public buildings, which is the basis for the analysis of energy consumption of large public buildings. According to the "State organs office buildings and large public buildings energy consumption monitoring system sub-energy data collection technology guide", large public buildings, energy consumption indicators are: the total building energy consumption, classification of energy consumption, sub-electricity , The unit area of electricity consumption, the unit air conditioning area electricity consumption, the unit area of electricity consumption, the unit area of energy consumption, energy consumption per unit area, energy 
consumption per unit area, unit air conditioning area sub-items Electricity consumption and so on.

\section{Large Public Building Energy Consumption Database}

Large-scale public building energy consumption monitoring is faced with the storage and management of massive and complex energy consumption data. As a method of computer-aided management of data, database technology plays an irreplaceable role in today's society, which needs to store massive information, The storage and management of energy consumption in public buildings provides an effective means of management. The establishment of a large public building energy consumption database, the first need for energy consumption database of the overall program design, specifically related to the application of the database system, service objects, the use of requirements and the ease of development and so on. This database is to store and manage the energy consumption information of large public buildings. Based on the database, it can realize the basic information query of several large public buildings in the area of the city, and run the classification energy consumption query, including the energy consumption and design of the equipment Parameter query, energy analysis and other functions. Subordinate energy management center (municipal) and superior energy management center (provincial and ministerial level) corresponds to different energy consumption database. This paper is based on the following level of energy management center (municipal) as an example, the establishment of a large server based on the large public building energy consumption database system for the region a number of large public building energy consumption management, including its lighting, heating, Air conditioning and other systems of energy consumption. In addition, in the large public building energy consumption database system overall design, select the appropriate database management software.

Database requirements analysis is the premise of database design and development. It is in the function, performance, behavior, design constraints and other aspects of the database application system requirements. Database requirements analysis is based on the understanding of the field of database applications, understanding and analysis of application areas, and the use of appropriate tools and symbols to systematically describe the database application system features, performance characteristics and constraints, which is the database system An important basis for design.

According to the database design system life cycle model of the three main design, the database application system needs analysis of the main contents include:

(1) data needs analysis analysis users need to obtain information from the database content and nature, that is, in the database need to store the application of data.

(2) data processing needs analysis from the user point of view of the need for data processing.

(3) business needs analysis from the application design point of view of the database application system business rules for analysis.

(4) analysis of the database system in the performance, storage, security, backup and recovery and other aspects of the content.

The data model is usually composed of three elements: data structure, data manipulation, and integrity constraints. The data structure is used to describe the static characteristics of the system. It expresses the relationship between the structure of the data object itself and the data object in the objective world, which is the most important aspect of the data model. Data structure can be divided into hierarchical structure, network structure, relational structure. Data manipulation is used to describe the dynamic characteristics of a system, which is a collection of data objects that allow operation rules in the database. The data integrity constraint is also a set of set of integrity rules that define the semantic constraints that the data model must adhere to. There are three data models commonly used in the database: hierarchical model, relational model, mesh model. Hierarchical model in the database appeared the earliest, it is characterized by: (1) root node only one, no parent node; (2) other nodes outside the root node only one parent node. The biggest advantage of the hierarchical model is that the relationship between the data is simple, the disadvantage is that for many-to-many links or a node corresponding to multiple parents, the hierarchy model representation is very troublesome. Relational model is the most commonly used data model of a 
database system, which uses a two-dimensional table to represent the relationship between entities and entities. The relational model is based on the two basic concepts of "set" and "relationship" in the theory of discrete mathematics collection. It has a mature and mature theoretical basis. The relational model uses the relationship to express the connection between entity and entity, Easy to understand and use. Relational model access path is for the user transparent, with good data independence and security and confidentiality. At present, the relational database system based on relational model is the mainstream database products on the market at present.

\section{Conclusion}

The energy conservation supervision of large public buildings is a complex system engineering problem. The study of energy consumption monitoring, model and operation management is beneficial to the low carbon, green and sustainable development of large public buildings in China. According to the energy consumption characteristics of large public buildings in China, the development of energy consumption monitoring system and the development of hard and software design, energy consumption database, energy consumption prediction model and management information system are mainly carried out.

\section{References}

[1] Xie Linlin, Peng Hongpu, Zhao Yue, Gao Chao. Public building health management research Taking Guangxi as an example [J]. Construction economy, 2011 (06)

[2] Qi Bin. Public buildings of the "public" thinking [J]. Urban architecture, 2011 (12)

[3] Yan Kun. Large space public building electrical design of a number of issues [J]. Fujian Construction Science and Technology, 2017 (03)

[4] Gan Huan. On the feasibility of public building project construction [J]. Private technology, 2016 (09)

[5] Liu Wenxia, Li Chunxiang. Improve the utilization rate of large public buildings [J]. Resource Conservation and Environmental Protection, 2015 (02)

[6] Du Hengqing, Liao Shui Nan. Public buildings why is always "sick" [J]. Construction workers, $2013(03)$ 